\title{
ANALISIS PENGARUH KEPUASAN KERJA, STRES KERJA, DAN MOTIVASI KERJA TERHADAP TURNOVER INTENTION KARYAWAN DI PT PRODIGI
}

\author{
Angelina Suseno \\ Program Study Magister Manajemen Universitas Tarumanagara \\ angelinasuseno@gmail.com
}

Masuk : 06-12-2020, revisi : 14-12-2020, diterima untuk diterbitkan : 59-12-2020

\begin{abstract}
The purpose of this study was to determine the effect of job satisfaction, job stress, and work motivation on the turnover intention at PT Prodigi, which is a challenge for companies in maintaining labor competition. This research is expected to be able to help determine the main factors causing employee turnover intention and overcome problems regarding turnover intention so that it can help companies reduce losses in terms of cost and time. The method in this study uses a cross-section method with quantitative research types and uses a questionnaire technique in collecting data. This study used 100 respondents. This study uses SPSS to perform statistical tests to get conclusions in knowing which dependent variables will affect the independent variables in the study. The result of the test that has been done is partial regression $(\mathrm{t})$ which shows that the variables of work stress and work motivation have a positive and significant effect on turnover intention and job satisfaction has a negative and insignificant effect on turnover intention.
\end{abstract}

Keywords: Job Satisfaction, Job Stress, Work Motivation, Turnover Intention

Abstrak: Tujuan dari penelitian ini adalah untuk mengetahui pengaruh kepuasan kerja, stres kerja, dan motivasi kerja terhadap turnover intention di PT Prodigi, yang menjadi suatu tantangan perusahaan dalam mempertahakan persaingan tenaga kerja. Penelitian ini diharapkan mampu membantu mengetahui faktor utama penyebab turnover intention karyawan dan mengatasi problematika mengenai turnover intention sehingga dapat membantu perusahaan mengurangi kerugian dari segi biaya maupun waktu. Metode pada penelitian ini menggunakan metode cross section dengan jenis penelitian kuantitatif dan menggunakan teknik kuesioner dalam mengumpulkan data. Pada penelitian ini menggunakan 100 responden. Penelitian ini menggunakan SPSS untuk melakukan uji statistik agar mendapatkan kesimpulan dalam mengetahui variabel dependen mana yang akan mempengaruhi variabel independen dalam penelitian. Hasil pengujian yang telah dilakukan adalah uji regresi parsial (t) menunjukkan bahwa variabel stres kerja dan motivasi kerja berpengaruh positif dan signifikan terhadap turnover intention dan kepuasan kerja berpengaruh negatif dan tidak signifikan terhadap turnover intention.

Kata Kunci: Kepuasan Kerja, Stres Kerja, Motivasi Kerja, Turnover Intention

\section{PENDAHULUAN}

Mempekerjakan karyawan sebagai sumber daya manusia dalam menjalin sebuah ikatan kerja merupakan unsur penting untuk menentukan keberhasilan suatu perusahaan. Sumber daya manusia mempengaruhi efektifitas dan efisiensi kegiatan operasional perusahaan, oleh karena itu kualitas karyawan merupakan aset utama bagi perusahaan sebagai kekuatan daya saing yang kuat dalam menghadapi berbagai ancaman eksternal. Dalam penelitian ini diharapkan mampu membantu mengetahui penyebab turnover intention karyawan dengan mengatasi masalah turnover intention karyawan sehingga dapat membantu perusahaan mengurangi kerugian dari segi waktu dan biaya.

Setiap perusahaan memiliki tantangan dalam menghadapi keinginan karyawan untuk 
meninggalkan pekerjaannya sehingga perlu adanya solusi agar manajemen perusahaan dapat mempertahakan keberlangsungan perusahaan.

\section{Tabel 1}

Data Turnover Intention Karyawan PT Prodigi Tahun 2017-2019

\begin{tabular}{|c|c|c|c|c|c|c|c|}
\hline \multirow{2}{*}{ No. } & \multirow{2}{*}{ Bulan } & \multicolumn{2}{|c|}{2017} & \multicolumn{2}{|c|}{2018} & \multicolumn{2}{|c|}{2019} \\
\hline & & In & Out & In & Out & In & Out \\
\hline 1 & January & 6 & 7 & 9 & 9 & 5 & 1 \\
\hline 2 & February & 4 & 5 & 3 & 4 & 9 & 2 \\
\hline 3 & March & 5 & 7 & 4 & 7 & 8 & 8 \\
\hline 4 & April & 8 & 4 & 5 & 7 & 4 & 7 \\
\hline 5 & May & 3 & 6 & 2 & 3 & 6 & 4 \\
\hline 6 & June & 4 & 3 & 3 & 5 & 3 & 9 \\
\hline 7 & July & 4 & 5 & 5 & 9 & 3 & 2 \\
\hline 8 & August & 4 & 5 & 8 & 5 & 4 & 8 \\
\hline 9 & September & 3 & 5 & 2 & 2 & 1 & 6 \\
\hline 10 & October & 5 & 3 & 1 & 9 & 5 & 7 \\
\hline 11 & November & 8 & 6 & 3 & 4 & 2 & 1 \\
\hline 12 & December & 4 & 8 & 2 & 3 & 1 & 5 \\
\hline & Total & 58 & 64 & 47 & 67 & 51 & 60 \\
\hline
\end{tabular}

Sumber: Data Perusahaan PT Prodigi tahun 2017 - tahun 2019

Dari tabel data di atas dapat disimpulkan pada tahun 2017 hingga tahun 2019 setiap bulan ada karyawan perusahaan yang mengundurkan diri. Hal ini menunjukkan bahwa turnover intention karyawan merupakan masalah yang perlu diperhatian agar manajemen perusahaan dapat mengantisipasi terjadinya turnover intention karyawan.

Berdasarkan uraian diatas maka penulis tertarik melakukan penelitian mengenai "Analisis Pengaruh Kepuasan Kerja, Stres Kerja, dan Motivasi Kerja terhadap Turnover Intention Karyawan di PT Prodigi".

\section{Tujuan Penelitian}

Tujuan penelitian ini untuk mengetahui adanya pengaruh antara kepuasan kerja, stres kerja, dan motivasi kerja terhadap turnover intention karyawan perusahaan sehingga diharapkan mampu mengetahui penyebab turnover intention karyawan perusahaan dengan mengatasi problematika mengenai turnover intention karyawan.

\section{TINJAUAN PUSTAKA}

Keinginan (intention) merupakan niat yang timbul dalam diri individu untuk melakukan sesuatu. Sedangkan perputaran (turnover) merupakan tindakan berhentinya seorang karyawan dari tempat bekerja secara sukarela atau pindah ke tempat kerja lain. Faktor yang mendasari keinginan berpindah karyawan adalah kepuasan kerja, stres kerja, kurangnya motivasi dalam bekerja dan sebagainya. Menurut Robbins dan Judge (2017), Turnover Intention merupakan suatu kecenderungan atau suatu tingkat dimana seorang karyawan memiliki kemungkinan untuk meninggalkan perusahaan baik secara sukarela maupun tidak sukarela karena kurang menariknya pekerjaan saat ini dan tersedianya alternatif pekerjaan lain. Hal tersebut dipengaruhi faktor ketidakpuasan karyawan dalam pekerjaan yang melibatkan gaji yang diterima, kesempatan pengembangan karir, hubungan dengan pegawai lainnya, jenis pekerjaan, struktur organisasi pekerjaan, dan mutu pengawasan. Kemudian faktor stres kerja juga memeiliki pengaruh terhadap turnover intention karena adanya tuntutan pekerjaan serta ketidaksesuaian antara harapan dan hasil yang diterima (Edison et al., 2016). Faktor terakhir yang dapat mempengaruhi turnover intention yaitu motivasi kerja karyawan sebagai proses yang dapat menjelaskan intensitas individu, arah, dan ketekunan karyawan dalam bekerja (Nawawi, 2015). Ketiga faktor tersebut memiliki keterikatan satu sama lain dan memiliki pengaruh terhadap turnover intention. 


\section{Kerangka Pemikiran \& Hipotesis Penelitian}

Dalam melakukan penelitian ini, kerangka pemikiran dapat digambarkan dengan bagan sebagai berikut:

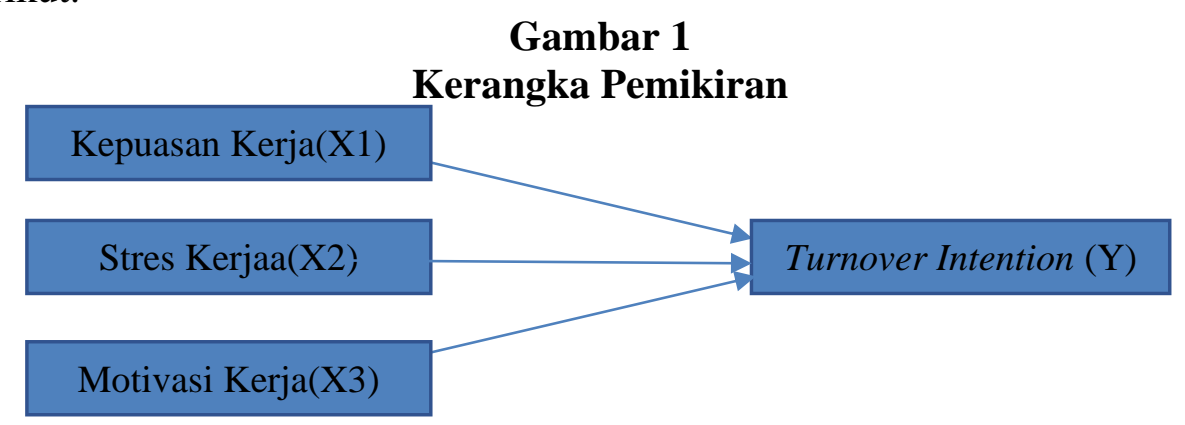

Dari kerangka pemikiran diatas, maka dapat dirumuskan hipotesis sebagai berikut:

H1: terdapat pengaruh negatif signifikan kepuasan kerja terhadap Turnover Intention karyawan.

$\mathrm{H} 2$ : terdapat pengaruh positif signifikan stres kerja terhadap Turnover Intention karyawan.

H3: terdapat pengaruh positif signifikan motivasi kerja terhadap Turnover Intention karyawan.

\section{METODOLOGI PENELITIAN}

Penelitian ini dilakukan dengan menggunakan metodologi penelitian kuantitatif dengan pendekatan kausal yaitu penelitian yang dilakukan guna menguji apakah satu atau beberapa variabel dapat menyebabkan terjadinya perubahan pada variabel lain. Penelitian ini menggunakan metode cross sectional dengan jenis penelitian kuantitatif dan menggunakan teknik pengumpulan data kusioner yang disebarkan kepada karyawan sejumlah 100 responden menggunakan SPSS.

\section{Hasil Uji Statistik \\ Uji Normalitas}

Tabel 2

Hasil Uji Normalitas

One-Sample Kolmogorov-Smirnov Test

\begin{tabular}{|c|c|}
\hline & Unstandardized Residual \\
\hline $\begin{array}{cc}\text { N } & \text { Mean } \\
\text { Normal Parameters }^{\mathrm{a}, \mathrm{b}} & \text { Std. Deviation } \\
& \text { Absolute } \\
\text { Most Extreme Differences } & \text { Positive } \\
& \text { Negative } \\
\text { Kolmogorov-Smirnov Z } \\
\text { Asymp. Sig. (2-tailed) }\end{array}$ & $\begin{array}{c}100 \\
, 0000000 \\
1,86665452 \\
, 086 \\
, 044 \\
-, 086 \\
, 086 \\
.066^{\mathrm{c}}\end{array}$ \\
\hline
\end{tabular}

a. Test distribution is Normal.

Sumber: Output SPSS yang diolah

Dari tabel di atas, terlihat nilai assymp sig $=0.066$. nilai tersebut $>0.05$, yang berarti data yang digunakan telah berdistribusi normal.

\section{Uji Multikolinearitas}

Tabel 3

Uji Multikolinearitas

\begin{tabular}{|c|c|}
\hline Model & VIF \\
\hline Kepuasan Kerja & 2.623 \\
\hline Stres Kerja & 2.825 \\
\hline Motivasi Kerja & 2.163 \\
\hline
\end{tabular}

Sumber: Output SPSS yang diolah

Dengan hasil uji multikolinearitas di atas, menunjukan bahwa persamaan model regresi tidak mengalami gejala multikolinearitas. Hal ini menjelaskan tidak ada korelasi antar variabel independen karena VIF < 10 sehingga variabel layak digunakan untuk analisis lebih lanjut. 


\section{Uji Heteroskedastisitas}

\section{Gambar 2}

Hasil Uji Heteroskedastisitas

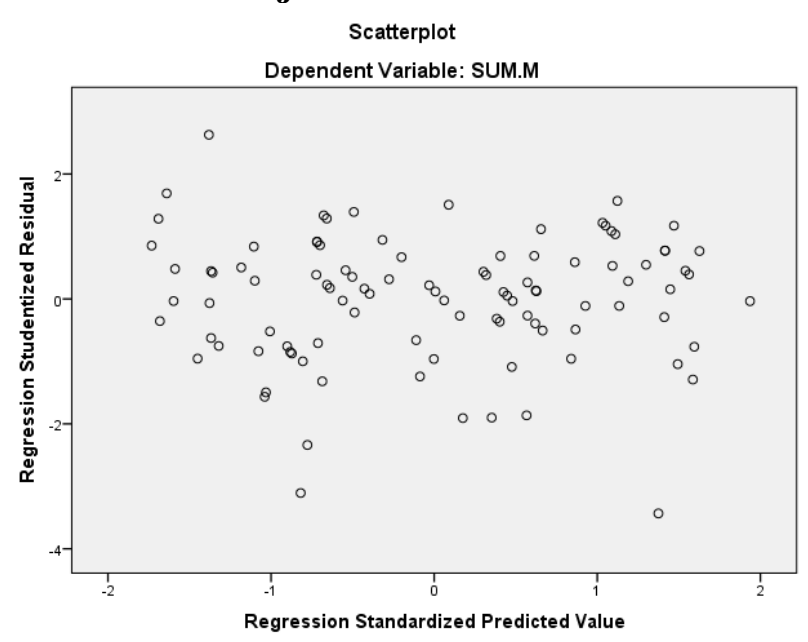

Sumber: Output SPSS yang diolah

Gambar di atas menggambarkan bahwa titik - titik menyebar di atas dan di bawah angka 0 pada sumbu Y dan tidak membentuk pola yang jelas. Hal ini menjelaskan bahwa tidak terjadi permasalahan heteroskedastisitas dalam model penelitian.

Analisis Koefisien Determinasi $\left(\mathbf{R}^{2}\right)$

\section{Tabel 4}

Nilai Koefisien Determinasi $\left(\mathbf{R}^{2}\right)$

Model Summary ${ }^{b}$

\begin{tabular}{|c|c|c|c|c|c|}
\hline Model & $\mathrm{R}$ & $\mathrm{R}$ Square & Adjusted R Square & Std. Error of the Estimate & Durbin-Watson \\
\hline 1 & $.932^{\mathrm{a}}$ & .869 & .865 & 1.89560 & 2.166 \\
\hline
\end{tabular}

a. Predictors: (Constant), Kepuasan Kerja, Stres Kerja, Motivasi Kerja

b. Dependent Variable: Turnover Intention

Sumber: Output SPSS yang diolah

Nilai $\mathrm{R}^{2}$ sebesar 0,869 . Hal ini berarti sebesar $86,9 \%$ variasi minat keluar karyawan (Y) dipengaruhi oleh ketiga variabel yaitu kepuasan kerja, stres kerja dan motivasi kerja sedangkan sisanya sebesar $13.1 \%$ dipengaruhi oleh variabel lain di luar model penelitian ini.

\section{Analisis Regresi Ganda}

\section{Tabel 5}

Hasil Analisis Regresi Linier

\begin{tabular}{|c|c|c|c|}
\hline & $\mathrm{B}$ & $\mathrm{t}$ & Sig \\
\hline (Constant) & 1.896 & 1.111 & .269 \\
\hline Kepuasan Kerja & -.045 & -.787 & .433 \\
\hline Stres Kerja & .754 & 12.499 & .000 \\
\hline Motivasi Kerja & .154 & 2.948 & .004 \\
\hline
\end{tabular}

Sumber: Output SPSS yang diolah

Dari hasil analisis didapatkan persamaan regresi sebagai berikut:

Minat keluar $=1.896-0.045($ Kepuasan $)+0.754($ Stres $)+0.154($ Motivasi $)$

\section{Hasil Uji F (uji Anova)}

\section{Tabel 6}

Uji F (ANOVA)

\begin{tabular}{|c|c|c|c|}
\hline \multicolumn{2}{|c|}{ Model } & F & Sig. \\
\hline \multirow{3}{*}{1} & Regression & 212.600 & $.000^{\mathrm{b}}$ \\
\cline { 2 - 4 } & Residual & & \\
\cline { 2 - 4 } & Total & & \\
\hline
\end{tabular}

Sumber: Output SPSS yang diolah 
Hasil data pada tabel di atas menunjukan bahwa nilai $\mathrm{F}$ hitung sebesar 212.600 dengan tingkat signifikansi sebesar $0,000<0,05$, yang berarti model yang terbentuk telah memenuhi model kelayakan regresi.

Hasil Uji t (uji Parsial)

Tabel 7

Hasil Uji t

\begin{tabular}{|c|c|c|c|}
\hline & B & $\mathrm{t}$ & Sig \\
\hline (Constant) & 1.896 & 1.111 & .269 \\
\hline Kepuasan Kerja & -.045 & -.787 & .433 \\
\hline Stres Kerja & .754 & 12.499 & .000 \\
\hline Motivasi Kerja & .154 & 2.948 & .004 \\
\hline
\end{tabular}

Sumber: Output SPSS yang diolah

Berdasarkan analisis di atas, maka dapat diartikan sebagai berikut:

1. Variabel kepuasan kerja (X1) memiliki nilai thitung sebesar $-0,787$. Artinya thitung $<\mathrm{t}$ tabel dan nilai signifikan 0,433>0,05 maka dapat disimpulkan bahwa hipotesis tidak diterima, variabel bebas kepuasan kerja secara parsial tidak berpengaruh signifikan terhadap turnover intention karyawan perusahaan.

2. Variabel stres kerja (X2) memiliki nilai thitung sebesar 12,499. Artinya thitung $>t_{\text {tabel }}$ dan nilai signifikan $0,000<0,05$ maka dapat disimpulkan bahwa hipotesis diterima, variabel bebas stres kerja secara parsial berpengaruh positif dan signifikan terhadap turnover intention karyawan perusahaan.

3. Variabel motivasi kerja (X3) memiliki nilai thitung sebesar 2,948. Artinya thitung $>t_{\text {tabel }}$ dan nilai signifikan $0,004<0,05$ maka dapat disimpulkan bahwa hipotesis diterima, variabel bebas motivasi kerja secara parsial berpengaruh positif dan signifikan terhadap turnover intention karyawan perusahaan.

\section{HASIL DAN KESIMPULAN}

Hasil dari melakukan uji validitas dan reliabilitas menunjukkan seluruh indikator telah memenuhi persyaratan validitas dan reliabilitas dengan nilai validitas keseluruhan di atas 0.195 dan cronbach's alpha $>0.600$.

Dari hasil analisis regresi ditemukan persamaan regresi yaitu: Minat keluar $=1.896-$ 0.045 (Kepuasan Kerja) + 0.754 (Stres Kerja) + 0.154 (Motivasi Kerja) yang disimpulkan bahwa nilai $\mathrm{Y}$ saat seluruh variabel independen $=0$ adalah 1.896. Nilai koefisien kepuasan kerja $=-0.045$ yang berarti saat variabel kepuasan kerja naik sebesar 1 satuan, maka variabel minat keluar akan menurun sebesar 0.045 . Nilai koefisien stres kerja $=0.754$ yang berarti saat variabel stres kerja naik sebesar 1 satuan, maka variabel minat keluar akan meningkat sebesar 0.754. Nilai koefisien motivasi kerja $=0.154$ yang berarti saat variabel motivasi kerja naik sebesar 1 satuan, maka variabel minat keluar akan meningkat sebesar 0.154.

Hasil pengujian variabel kepuasan kerja (X1) terhadap turnover intention (Y) memiliki tingkat signifikan sebesar 0,433 , lebih besar dari $\alpha(\alpha=0,05)$ sehingga H1 ditolak. Artinya kepuasan kerja tidak berpengaruh terhadap turnover intention karyawan secara signifikan. Hasil penelitian ini tidak sesuai dengan penelitian sebelumnya yang dilakukan oleh O'Connor (2018) yang menyatakan kepuasan kerja memiliki pengaruh negatif signifikan terhadap turnover intention karyawan. Hal ini dapat terjadi karena kepuasan kerja karyawan tidak menjadi faktor penting karyawan saat ini untuk berpindah tempat kerja namun terdapat faktor lain yang lebih penting seperti sulitnya karyawan mencari lapangan kerja baru yang sesuai dengan harapan mereka saat ini sehingga membuat para karyawan perusahaan tetap mempertahankan pekerjaannya. 
Hasil pengujian stres kerja (X2) terhadap turnover intention (Y) memiliki tingkat signifikan sebesar 0,000 , lebih kecil dari $\alpha(\alpha=0,05)$ sehingga $\mathrm{H} 2$ diterima. Artinya stres kerja berpengaruh terhadap turnover intention karyawan secara signifikan. Hasil penelitian ini sesuai dengan penelitian sebelumnya yang dilakukan oleh Perera (2017) yang menyatakan stres kerja berdampak positif signifikan terhadap minat keluar karyawan. Karyawan yang mengalami stres dalam bekerja cenderung akan mencoba mencari lapangan pekerjaan yang baru walaupun dengan upah gaji yang sama atau lebih rendah namun yang terpenting bagi karyawan yaitu tidak menimbulkan stres kerja yang tinggi di perusahaan selanjutnya.

Hasil pengujian motivasi kerja (X3) terhadap turnover intention (Y) memiliki tingkat signifikan sebesar 0,004 , lebih kecil dari $\alpha(\alpha=0,05)$ sehingga $\mathrm{H} 3$ diterima. Artinya motivasi kerja berpengaruh terhadap minat keluar karyawan. Hasil ini penelitian ini sesuai dengan penelitian yang dilakukan oleh Evelyn (2013) yang menyatakan motivasi kerja berpengaruh terhadap turnover intention karyawan. Hal ini terjadi karena adanya dorongan motivasi kerja kepada karyawan mengenai batasan-batasan yang diberikan sehingga karyawan menjadi lebih bersemangat dalam bekerja sehingga dapat mencapai tujuan organisasi perusahaan secara maksimal.

\section{SARAN}

Setelah mengetahui hasil dari penelitian ini, maka saran yang dapat diberikan sebagai berikut:

1. Dari segi kepuasan kerja, pihak perusahaan disarankan untuk meningkatkan kepuasan intrinsik maupun ekstrinsik karyawan dengan memberikan penghargaan, menaikkan gaji, menaikkan jabatan, serta memerhatikan hak-hak karyawan baik finansial maupun nonfinansial untuk menjaga tingkat kepuasan karyawan.

2. Dari segi stres kerja, pihak perusahaan disarankan mengadakan acara kebersamaan, liburan bersama, serta memberikan suasana kerja yang lebih kondusif dengan meningkatkan fasilitas dan dukungan dari atasan untuk meringankan beban pekerjaan karyawan.

3. Dari segi motivasi kerja, pihak perusahaan perlu menciptakan iklim komunikasi organisasi yang terbuka, medukung dan memberikan perhatian dalam menjaga sikap dalam berkomunikasi

4. Untuk penelitian selanjutnya, disarankan untuk meneliti variabel lain yang mungkin bisa berpengaruh terhadap minat keluar karyawan, sehingga dapat menemukan prediktor lain yang berpengaruh terhadap minat keluar karyawan seperti variabel komitmen organisasi, upah yang diterima, dan lain sebagainya.

\section{DAFTAR PUSTAKA}

Edison, E., Yohny, \& Imas. (2016). Manajemen sumber daya manusia. Alfabeta CV.

Evelyn. (2013). Pengaruh motivasi kerja terhadap kinerja karyawan pada PT Bank Mandiri

(Persero) TBK kantor wilayah X Makassar. Universitas Hasanuddin.

Nawawi, H. (2015). Manajemen sumber daya manusia. Gadjah Mada University Press.

O'Connor, J. (2018). Pengaruh kepuasan kerja dan motivasi kerja terhadap turnover intention. GSFT Journal Of Business, 12(2).

Perera, D. (2017). Pengaruh kepuasan kerja, stres kerja dan komitmen organisasi terhadap turnover intention. Universitas Yogyakarta.

Robbins, S. P., \& Judge, T. A. (2017). Organizational behavior (15th ed.). Pearson Education, Inc. 